\title{
VIAGEM AO CENTRO DO POLISSISTEMA: O PAPEL DAS ADAPTAÇÕES CINEMATOGRÁFICAS NA DINÂMICA DE SISTEMAS LITERÁRIOS E CULTURAIS
}

\author{
Elaine Barros Indrusiak ${ }^{*}$
}

\begin{abstract}
This paper aims at presenting and discussing the first findings of a research project that employs Itamar Even-Zohar's Polysystem Theory (1978; 2010) in mapping some of the contributions cinema industry has brought to the Brazilian literary system. Focusing on the editorial boom and renewal of J. R. R. Tolkien's trilogy The Lord of the Rings (1954) brought about by Peter Jackson's homonymous film versions (2001-2003), the research intends to demonstrate that adaptations of literary works to the screen may renew and enrich the original text, rearrange its role and position within both source and target literary systems by introducing it to new audiences, adapting it to new readers, performing that which Walter Benjamin (2000) conceived as translation's major role: to grant the original text "afterlife".
\end{abstract}

\section{KEYWORDS: literary polysystem, adaptation, cinema, J. R. R. Tolkien}

A vertente comparatista dos estudos literários sempre foi particularmente rica em solo brasileiro, mesmo porque, como já argumentava Antonio Candido: "estudar literatura brasileira é estudar literatura comparada" (1993, p. 211). Em função disso, a prestigiada Associação Brasileira de Literatura Comparada (ABRALIC) tem servido de bússola confiável aos marinheiros em águas literárias, apontando sempre as mais recentes tendências e orientações da pesquisa acadêmica e do pensamento crítico voltados não apenas ao texto literário em si, mas também às relações inter- e multidisciplinares que, se não inaugurou, a pós-modernidade soube multiplicar e aprofundar sobremaneira. Nesse sentido, ao observarmos que os dois últimos eventos de maior abrangência da ABRALIC, o XII Encontro (2010) e o XII Congresso Internacional (2011), versaram sobre a temática Centro, centros, parece acertado concluirmos que há hoje uma preocupação pronunciada quanto às relações de poder que determinam a formação de centros, os quais, evidentemente, se constituem por oposição a zonas periféricas.

Certamente, tanto o bom-senso quanto um exame superficial das produções resultantes desses e outros eventos acadêmicos nos informam que a proposição da dicotomia centro $v s$. periferia como temática dá margem a uma ampla gama de possibilidades investigativas, desde o já amadurecido questionamento quanto às

\footnotetext{
* Professora da Universidade Federal do Rio Grande do Sul (UFRGS).
} 
literaturas nacionais no âmbito de uma pretensa Weltliteratur até indagações mais recentes quanto às relações que se estabelecem entre textos de naturezas diversas e que também definem hierarquias, centros e periferias. Oriundos do que se convencionou chamar "país de cultura transplantada", os estudos literários brasileiros sempre demonstraram especial interesse pelas discussões comparatistas que visavam conferir à literatura nacional seu "lugar ao sol" nas relações com as literaturas estrangeiras, particularmente as europeias, por muito tempo vistas como o próprio sol em torno do qual estávamos fadados a orbitar, o que se depreende da própria colocação de Candido acima referida. Nesse cenário, a prática tradutória e os Estudos de Tradução, campo de estudos sempre muito próximo das investigações comparatistas, pareciam sofrer da maldição de la Malinche - ao tradutor cabem a honra e a glória de propiciar a comunicação entre os povos e culturas, mas também recaem sobre suas costas as acusações de entreguismo e a responsabilidade pela dominação da periferia pelo centro.

Apesar do humor anárquico de Oswald de Andrade em suas proposições antropofágicas, que ainda em 1928 afirmava "só me interessa o que não é meu" (2008, p. 3-5), apenas recentemente começamos a nos libertar dessa visão eivada de culpa, subserviência, inferioridade e dívida. Infelizmente, no entanto, mesmo essa libertadora mudança de perspectiva se deu muito mais em função de fatores extrínsecos, em particular as novas concepções de influência forjadas sob a esmagadora e revolucionária lógica da intertextualidade, do que por uma tomada de consciência que efetivamente celebrasse nossa condição de "imitadores". Em outras palavras, a moratória da dívida cultural que pairava sobre nossa literatura não foi decretada por nós mesmos, mas nos foi concedida pelo pensamento teórico-crítico de origem europeia e norte-americana, nosso credor.

Mais recentemente, no entanto, seja pelos efeitos da lógica pós-colonialista, que questiona e subverte dívidas e filiações, seja em função de um pensamento pósmodernista importado em larga escala, embora talvez um tanto precocemente, tendo em vista que ainda não esgotamos nossa modernidade, o questionamento quanto à constituição de centros e periferias no âmbito da própria literatura nacional vem ganhando força. Tal tendência é ainda reforçada pelos aportes interdisciplinar e intersemiótico que, sem negar fronteiras e especificidades linguísticas e textuais, segue o texto aonde quer que ele vá, seja sob a forma de tradução, intertexto ou mesmo de influência, extrapolando, com isso, os limites do literário para abarcar o cenário mais amplo - e, consequentemente, mais complexo - do cultural. Nesse contexto, as proposições teóricas do pesquisador israelense Itamar Even-Zohar acerca de polissistemas literários revestem-se de grande relevância, subsidiando as investigações quanto às relações de poder e às atribuições de valor entre os diferentes textos que compõem os sistemas literários e culturais, os quais se caracterizam pela pluralidade e diversidade de conjuntos de elementos em relação dinâmica e hierarquicamente organizados, constituindo o que o pesquisador classifica como "sistemas de sistemas" e, por isso, "polissistemas".

Aquilo que posteriormente se convencionou chamar Teoria dos Polissistemas foi sistematizado a partir de diversos textos publicados por Even-Zohar ao longo da década de 70, os quais têm sido sistematicamente revistos, aprofundados e ampliados até o presente. Fruto dos estudos de forte influência formalista da chamada Escola de Tel Aviv, as teorizações de Even-Zohar nasceram alinhadas aos Estudos Descritivos de Tradução (Descriptive Translation Studies - DTS), propostos por Gideon Toury, e focavam questões tradutórias que definiram as condições e $o$ cenário de 
desenvolvimento da então incipiente literatura hebraica, em particular as relações de poder que se estabeleceram entre essa literatura e aquelas produzidas em outras línguas que coexistem e circulam no ainda recente polissistema literário israelense. Apesar da visão sistêmica e contextualizada dos fenômenos tradutórios, literários, linguísticos, culturais e mesmo econômicos que influenciaram o desenvolvimento da literatura em foco, afastando-se, por vezes, dos textos fonte e alvo, a análise de Even-Zohar mantém a neutralidade e objetividade descritivas postuladas pelo colega Toury e que evocam o pendor científico formalista. Não há, portanto, julgamentos de valor nem posicionamentos ideológicos abertamente invocados e/ou defendidos, mas a tentativa de se mapear as tensões existentes entre os elementos que compõem o polissistema literário. Entretanto, estando ainda em plena atividade, Itamar Even-Zohar tem ampliado consideravelmente o escopo de sua teoria, não mais limitando sua investigação apenas aos polissistemas literários em suas relações diacrônicas e sincrônicas, mas abarcando também as relações de poder que se estabelecem no âmbito da cultura como um todo, o que dá margem à caracterização de verdadeiros polissistemas culturais, como atesta sua recente publicação Papers in Culture Research (2010).

Muitas vezes, a dinâmica de constituição de centro(s) e periferia(s) dentro dos polissistemas literários espelha relações de poder de caráter colonialista e/ou imperialista, já que textos em línguas de maior prestígio ou oriundos de sistemas literários de reconhecido valor cultural tendem a se instalar confortavelmente próximos ao topo da hierarquia de obras que compõem um sistema literário ainda em processo de consolidação. A questão, no entanto, é mais complexa, já que, como aponta o pesquisador, há ainda outros casos em que a literatura traduzida goza de posicionamento central em detrimento da produção local em um sistema literário:

It seems to me that three major cases can be discerned: (a) when a polysystem has not yet been crystallized, that is to say, when a literature is "young," in the process of being established; (b) when a literature is either "peripheral" or "weak," or both; and (c) when there are turning points, crises, or literary vacuums in a literature (EVEN-ZOHAR, 1978, p. 21).

Com isso, a tradução como prática cultural reveste-se de enorme relevância, pois é por meio dela que o centro do sistema é alimentado de obras que servirão de modelo e contraponto àquelas que orbitam nas zonas periféricas ou que suprirão eventuais carências desse sistema. Percebe-se, assim, a grande contribuição trazida pela Teoria dos Polissistemas para o estudo da formação e da organização atual do sistema literário brasileiro, forjado à sombra da literatura europeia e dependente da tradução e da importação. Evidentemente, o cenário de formação de nosso sistema literário já não corresponde à situação atual; cabe indagar e averiguar, de forma detida e criteriosa, em que medida a literatura traduzida ainda ocupa posição centralizada em nosso polissistema, tendo em vista os inegáveis progresso e amadurecimento da literatura nacional. De qualquer forma, mesmo um passeio descompromissado entre prateleiras de grandes livrarias nos principais centros urbanos do país parece apontar indícios de que ainda estamos muito aquém de uma inversão dessa situação, e que a literatura traduzida ainda há de ocupar posição privilegiada em nossa cultura por vários anos.

Mais do que subsidiar as pesquisas voltadas para esse fenômeno de trocas internacionais, no entanto, o arcabouço teórico dos estudos de Even-Zohar contribui ainda para a verificação de que também a produção nacional se distribui em regiões centrais ou periféricas no interior do sistema literário, evidenciando a mesma dinâmica 
de hierarquização que orienta o posicionamento dos textos estrangeiros importados via tradução, como se depreende do status conferido à literatura juvenil ou a manifestações escritas de cultura popular, como o cordel. Conclui-se, portanto, que os julgamentos de valor, as atribuições de prestígio e a formação de cânones que regem as relações internas dos polissistemas literários derivam de jogos de poder que vão bem além de noções simplistas de dominação cultural e/ou econômica entre nações.

Vivemos, no entanto, tempos de exacerbada interdisciplinaridade, em que novas concepções de texto põem em xeque os pressupostos do literário, como analisa a semioticista Dinda Gorlée:

\begin{abstract}
Hoje qualquer sequência de palavras - Guerra e paz, um haikai, a letra de uma canção dos Beatles, o Diário de Anne Frank, uma lista de supermercado, uma entrevista de rádio, uma receita médica — pode se qualificar como um texto e consequentemente ser filtrada pela mesma malha processadora de textos. O mesmo cabe aos fenômenos não-verbais e parcialmente verbais, tais como uma história em quadrinhos, uma representação teatral, a paisagem urbana, ou uma roupa (apud SANTAELLA, 1992, p. 392).
\end{abstract}

Some-se a isso o fato de que também os mercados culturais, orientados pelas lógicas da globalização e da massificação, parecem apostar na exploração de aproximações e sinergias com vistas à maximização de suas campanhas de marketing e do potencial de venda de seus produtos. Consequentemente, parece-nos absolutamente natural e coerente que as constatações de Even-Zohar quanto aos polissistemas literários migrem e sejam também aplicáveis a instâncias maiores e mais complexas que englobem todos os demais sistemas semióticos de comunicação e produção artística:

[...] the polysystemic approach is expected to serve as the theoretical environment for the study of culture allowing it to develop versatile tools which will enable dealing with heterogeneity and dynamics along the same principles that have led to the furtherance of the cultural framework (EVENZOHAR, 2010, p. 39).

Assim, é com base em tais pressupostos teóricos que nos dedicamos ao estudo de contribuições da indústria cinematográfica ao polissistema literário brasileiro por meio de adaptações de obras literárias de língua inglesa. Embora estudos quanto às relações entre essas duas artes sejam hoje absolutamente recorrentes em nosso meio acadêmico, em parte pelo reconhecimento dos méritos investigativos da abordagem interdisciplinar, em parte pela inescapável penetração e influência cultural do cinema como expressão artística, procuramos ir além da ainda corriqueira percepção de que tal diálogo interdisciplinar está pautado por uma relação parasitária em que o cinema - arte e indústria de recente formação - se beneficia do legado literário, mais antigo e prestigioso, ao tomar emprestados histórias, enredos, personagens e recursos narrativos. Para tanto, buscamos na abordagem sistêmica ferramentas que nos permitam descrever a complexa rede de relações existentes entre literatura e cinema, demonstrando que, a despeito de preconceitos que ainda se fazem sentir em algumas instâncias do complexo sistema cultural, a massificada sétima arte tem auxiliado o mercado editorial a minimizar o impacto que a exacerbação da cultura visual, assim como novas tecnologias e formas de entretenimento, têm tido na leitura e, consequentemente, nos sistemas literários.

A relação entre literatura e cinema é tão antiga quanto a própria sétima arte, 
como salienta Gerald Mast em seu célebre e seminal ensaio quanto a esse diálogo interdisciplinar e intersemiótico:

\begin{abstract}
Since moving pictures and, after 1927, moving pictures synchronized with recorded sounds could be used to tell stories, describe events, imitate human actions, expose problems, and urge reforms, it is not surprising that such uses of motion pictures would provoke speculative comparisons with that other major human system for telling, describing, imitating, exposing, and urging verbal language. The history of these comparisons between film and literature has been a history of splitters and lumpers, of those who argue for the distinctness of the two media - the effects, purposes, pleasures, and possibilities of two separate arts that are, ought to be, or must be distinct - as opposed to those who argue that the aims, effects, and means of the two media are similar, parallel, or analogous (MAST, 1982, p. 278).
\end{abstract}

Embora esse diálogo, como aponta Mast, derive das próprias estruturas textuais e possibilidades comunicativas das duas artes envolvidas, dando margem a uma vasta gama de relações, paralelos e influências que em muito tem contribuído para suas respectivas produções, por razões que sequer o pesquisador sabe apontar, um enorme percentual das abordagens teórico-críticas a tais relações limita o termo literatura a romances e textos dramáticos, enquanto o vocábulo filme é reduzido apenas à categoria de filmes narrativos ficcionais, especialmente os de longa-metragem. Pouco se debate acerca dos possíveis diálogos entre o documentário e textos literários, ou da poesia com, digamos, obras de animação, para citar apenas duas das outras tantas possibilidades investigativas. Mais do que isso, no entanto, mesmo uma análise superficial da numerosa produção dedicada a tais estudos parece ser suficiente para comprovarmos a tendência a se privilegiar os casos de adaptação de obras literárias (romances e peças) para a linguagem cinematográfica, solenemente ignorando a vasta gama de diálogos possíveis, de intertextos visíveis a sutis influências, o que, em última análise, contribui para essa insidiosa noção de que a miríade de relações entre dois vastos campos da criação artística humana possa ser limitada à prática da tradução intersemiótica que vise tão-somente a recontar na grande tela o que a literatura já consagrou anteriormente em suas páginas. Em um mundo ainda fortemente apegado à noção de uma hipervalorizada e idealizada originalidade que se confunde com primazia, não são necessárias grandes lucubrações mentais para se localizar aqui um confortável nicho para a noção de dívida cultural nos mesmos moldes do que aquela que ainda hoje solapa muitos dos sistemas literários não-europeus. Em outras palavras, essa visão parcial da riqueza do diálogo interdisciplinar reforça a percepção de que o cinema deve à literatura muito de sua riqueza e complexidade simplesmente, ora vejam, por lhe ser posterior.

Evidentemente, o mercado de adaptações cinematográficas para obras literárias, bem como a obviedade de tais diálogos, muitas vezes expressos nas próprias escolhas de títulos (Mary Shelley's Frankenstein, por exemplo), justifica, ao menos em parte, essa preferência, mas há ainda outras razões, de ordem histórica, que parecem contribuir para tão acentuada tendência. A primeira delas, como salienta Mast, é o fato de o cinema, sendo uma arte recente, não apenas ser avaliado e julgado por critérios aplicáveis às artes mais antigas e prestigiosas, mas também ser estudado por profissionais que tiveram seu gosto e sua formação orientados pelas especificidades das formas artísticas já consagradas e das disciplinas a elas dedicadas, notadamente a literatura. Também a distinção de públicos se faz notar aqui, já que as preocupações estéticas, filosóficas e epistemológicas são características dos mais seletos e afluentes públicos das artes 
prestigiosas, enquanto as plateias cinematográficas que caracterizaram os primórdios da sétima arte - não raro analfabetas - não se ocupavam de questionamentos da tal ordem, pouco se importando com o status sócio-cultural de seu recentemente adquirido passatempo. No caso específico das adaptações, apropriações e outros diálogos intertextuais explícitos, soma-se a isso a própria visão desprestigiada que a tradução neste caso em sua modalidade intersemiótica - ainda não logrou superar, em função da vigência de uma percepção do texto literário original como algo sagrado cuja integridade não deva ser conspurcada; a velha máxima da fidelidade, que por mais falaciosa que os Estudos de Tradução já tenham demonstrado ser, continua a ser desejada e defendida por muitos, nem sempre de forma velada.

Mast lista ainda como fator depreciativo do cinema frente à literatura o pressuposto modernista, ainda muito em voga, de que uma obra de arte deva ser uma criação radical, em forma e conteúdo, que não derive de convenções genéricas e, por isso mesmo, não encontre identificação junto às massas, as quais tendem a se sentir confortáveis na presença do genérico e do convencional (MAST, 1982, p. 281). Embora não se alongue na análise dessa questão, enfatizando apenas que o experimentalismo formal não é exatamente a marca da maior parte da produção da indústria cinematográfica, pode-se perceber aqui que o pesquisador tangencia um aspecto de grande relevância para esta pesquisa: a caracterização do cinema como expressão cultural massificada. Em textos anteriores (INDRUSIAK, 2001; 2009), já me detive em analisar algumas das desastrosas consequências, particularmente para o cinema, de posicionamentos abertamente preconceituosos quanto à chamada cultura de massa por parte de brilhantes e influentes pensadores. Talvez o melhor exemplo disso seja o célebre ensaio A indústria cultural: o iluminismo como mistificação de massas, de Max Horkheimer e Theodor Adorno (2000), no qual os autores realizam uma complexa e articulada reflexão quanto aos fatores sociais, históricos, econômicos e culturais que levaram à formação da cultura de massa para concluírem, de forma cabal e altamente convincente, que arte e entretenimento não são apenas fenômenos culturais distintos, mas inconciliáveis (HORKHEIMER e ADORNO, 2000, p. 184).

Apesar de tantos e tão arraigados princípios e preconceitos que por muitos anos negaram ao cinema o status de arte, pode-se dizer, com alívio e genuína satisfação, que essa discussão se mostra hoje superada. Ainda que o termo "indústria" cinematográfica continue a assombrar e desassossegar eventuais puristas de plantão, a sétima arte parece já fazer jus à sua própria musa. Preconceitos, no entanto, não morrem facilmente, e não raro seus propagadores fazem pequenas concessões a fim de manter intocáveis seus valores mais recônditos, a velha tática de "dar os anéis para não perder os dedos". Esse parece ter sido o caso da percepção de valor do cinema como produto cultural massificado. Em vez de se abolir avaliações apriorísticas que pré-julgam e rotulam produções em função de sua popularidade junto a públicos menos afluentes e sofisticados, o que se fez, paulatinamente, foi dividir a produção cinematográfica em dois segmentos facilmente identificáveis, os chamados "filmes de arte" e os "filmes comerciais", um desdobramento do avassalador crescimento e da diversificação da produção cinematográfica mundial que, infelizmente, corrobora a noção de que arte e entretenimento sejam auto-excludentes. Embora nem mesmo a literatura especializada defina de forma cabal que tipos de filmes alinham-se em cada um desses segmentos, mesmo porque classificações genéricas em estudos de cinema são ainda processos em franco desenvolvimento, qualquer leitor de suplementos culturais saberá preencher a segunda categoria com os filmes hollywoodianos e os blockbusters; ao passo que a 
definição dos componentes do primeiro grupo seria um tanto mais complicada por envolver a própria noção de arte cinematográfica. Entretanto, essa tarefa pode ser consideravelmente simplificada, sem maiores riscos de erro, se ali amontoarmos as produções europeias (francesas, em especial), asiáticas (excetuando-se os já mundialmente conhecidos filmes de Bollywood), independentes, experimentais e "de autor", ou seja, quase todos os filmes que não tenham sido criados por estúdios norteamericanos e/ou não tenham obtido muito sucesso e retorno financeiro. Exageros e imprecisões à parte, pode-se dizer que a indústria cinematográfica contemporânea, bem como sua crítica especializada, está pautada por essa lógica classificatória.

É interessante salientar, no entanto, que o cinema constitui uma arte e também uma indústria. Assim, tanto o experimentalismo e apuro estético e narrativo peculiar aos filmes de arte, quanto os pesados investimentos em novas tecnologias de produção e de reprodução audiovisuais, possíveis apenas em filmes comerciais bancados por grandes produtores, contribuem igualmente para o desenvolvimento da linguagem cinematográfica. Apesar disso, a mesma pecha de entretenimento desprovido de qualidades artísticas que outrora recaía sobre o cinema como um todo hoje é empregada na caracterização a priori dos filmes comerciais, em particular os blockbusters. Evidentemente, não queremos com isso advogar a inversão total desse discurso, defendendo a tese de que todos os filmes cinematográficos seriam obras de arte passíveis das mais criteriosas análises e considerações teórico-críticas. Assim como todas as demais artes, o cinema produz uma grande quantidade de obras sofríveis, de qualidade e mérito altamente questionáveis, independentemente de terem ou não apelo comercial. O que questionamos é a prática, nem sempre velada, de se avaliar qualidade e valor artísticos a partir de dados financeiros em uma relação de proporcionalidade inversa: quanto maiores as cifras envolvidas na produção ou na arrecadação de um filme, menor será seu mérito como obra de arte.

Embora essa seja uma questão interna da indústria e do mercado cinematográficos, a literatura não lhe é indiferente. As tão numerosas adaptações e apropriações de obras literárias, por exemplo, estão sujeitas às mesmas regras aplicáveis aos roteiros originais, mas com um agravante: a nenhum leitor parece agradar o fato de uma de suas leituras favoritas subitamente ser transformada em um blockbuster. Imaginemos, apenas a título de sutil divertimento, as reações apaixonadas que geraria o anúncio de uma produção de Hamlet, por exemplo, tendo o experiente ator Sylvester Stallone como protagonista. Nem mesmo as muitas lições de Alfred Hitchcock demonstrando que, em cinema, talento dramatúrgico não é condição sine qua non para a produção de um grande filme, salvariam essa obra. Mesmo antes de qualquer tomada ser feita, o filme e seu diretor já estariam irremediavelmente fadados ao massacre da crítica. Certamente, um exemplo assim tão improvável chega a ser risível, mas é suficiente para percebermos a existência dessa premissa segundo a qual a adaptação de grandes obras literárias para o cinema deve pautar-se por um tratamento artístico, não comercial, seja lá o que, exatamente, isso venha a acarretar em termos de roteirização, tradução intersemiótica e produção cinematográfica.

O hipotético exemplo acima explicita ainda aquilo que Christian Metz (1972) aponta como cerne da distinção entre linguagens fílmica e cinematográfica. O texto cinematográfico vai muito além do texto fílmico, pois envolve também elementos que produzem significados antes, durante e após a projeção do filme em si, tais como as condições de projeção ou mesmo os pressupostos e intertextos gerados pela mera escolha de atores para os diferentes papéis, como em nosso cômico exemplo. Percebe-se, 
com isso, que criticar o cinema comercial por fazer uso de elementos extrínsecos ao filme a fim de maximizar a experiência cultural a ele atrelada não faz sentido algum, pois esse é um mecanismo inerente à produção de sentido na arte cinematográfica.

Diante desse cenário, é ingrata a posição do diretor que se proponha a adaptar para a linguagem cinematográfica obras literárias canônicas e/ou de grande popularidade. Se tiver pretensões de um dia vir a ser aclamado como auteur, quase desejará que sua obra seja um fracasso de público para que apenas a crítica e mais alguns poucos aficionados vejam ali o pendor "não-comercial" que irá consagrá-lo. Entretanto, se isso é uma regra do mercado cinematográfico, há de haver ao menos uma exceção que a confirme. Pois acreditamos ter encontrado, na Nova Zelândia, uma de tais exceções, que atende pelo nome Peter Jackson.

Ilustre desconhecido diretor de filmes $B$ (um "artista", portanto) sem qualquer título de maior impacto no currículo, Peter Jackson viu-se, em meados dos anos 90, colocado à frente de um multimilionário orçamento e de uma das maiores empreitadas cinematográficas já realizadas, a produção simultânea de três filmes de longa-metragem que transporiam para a tela, da forma mais fiel possível, a saga $O$ senhor dos anéis, de $\mathrm{J}$. R. R. Tolkien. Desde os primeiros rumores a respeito dessa adaptação muito aguardada, mas até então inédita, dados os desafios tradutórios que o romance apresentava, pairavam no ar fortes suspeitas quanto ao porquê da escolha de Jackson e quanto aos seus atributos para assumir tamanha responsabilidade. Embora a obra de Tolkien tenha sempre sido alvo de acirradas disputas quanto ao seu valor literário e nunca tenha gozado de posição inquestionavelmente central mesmo em seu sistema literário de origem, sua apaixonada legião de fãs britânicos a elevou à singular posição de "livro do século" . Os riscos de vultosos prejuízos financeiros e de a adaptação transformar-se em uma "crônica de um fiasco anunciado" eram astronômicos. A escolha do diretor, portanto, não poderia ser descuidada, mas obedeceu a um criterioso processo de seleção que levou em conta tanto características necessárias para se garantir a aceitação do público literário quanto aquelas que assegurariam o retorno financeiro necessário e almejado pelos produtores e investidores, como aponta I. Q. Hunter:

Jackson and his co-adaptors were constrained not only to satisfy Tolkien readers by capturing "the essence" of the novel, but also to produce a blockbuster action movie accessible to viewers with no emotional investment in the novel. But the novel's wide fan base, while not sufficient, as Kristin Thompson remarks, to make the film a hit, was certainly large enough to cause damage if the film was felt to be inauthentic, "Hollywoodized" and out of alignment with readers' expectations [...] To keep the fans onside, it was crucial not only that the films (or at least the first one) stuck closely to the novel, but that Jackson and his team display credentials as fans themselves. The Tolkien estate, luckily, had no control over the films, but convenient links were emphasized between Tolkien and the filmmakers - for example, the fact that Christopher Lee, who plays Saruman, had actually met Tolkien. Jackson himself was opportunistically spun in publicity material as a genial, tubby, bare-footed hobbit. Even so, while mollifying the fans ensured some sort of audience for the film, pandering exclusively to them was aesthetically constricting and commercially perilous [...] Furthermore, for a minority of film fans (like me), The Lord of the Rings was not simply an adaptation of Tolkien: it was the latest film by the auteur Peter Jackson, an accomplished director of fantasy movies from the splatter-comedy Bad Taste (1987) to the

\footnotetext{
${ }^{1}$ Em pesquisa realizada em 1997 pelo canal de TV britânico Channel 4 em parceria com a rede de livrarias Waterstone, que visava apontar "o maior livro do século XX”, na opinião do público leitor.
} 
psychological drama Heavenly Creatures (1994). How would Lord of the Rings adapt to and extend his distinctive vision? Was the quirkily subversive New Zealander at last selling out to Hollywood? (HUNTER, 2007, p. 156-7).

Contrariando as mais pessimistas previsões, no entanto, a escolha de Jackson mostrou-se mais do que acertada, e ao final de 2003, ano de lançamento do último filme da trilogia, a versão cinematográfica de $O$ senhor dos anéis consagrava-se como uma das mais bem sucedidas adaptações de obras literárias, uma grande obra de ficção, um prodígio de criação audiovisual de mundos e seres fantásticos e, paradoxalmente, um blockbuster de grandes qualidades artísticas. Evidentemente, Jackson não esteve sozinho ao longo dos vários anos que tamanha produção demandou, e parte do sucesso da trilogia deve ser atribuída à competente campanha de marketing que orquestrou todos os movimentos dos diversos produtos culturais criados em associação à obra cinematográfica. Atento ao potencial de vendas dessa grande movimentação cultural, o mercado editorial apressou-se em lançar também os seus produtos: uma ampla variedade de edições da trilogia original, reedições de outras obras de Tolkien, assim como publicações com temáticas afins à de $O$ senhor dos anéis.

Até aqui, nada de novo; booms editoriais alimentados por adaptações cinematográficas constituem um fenômeno bastante corriqueiro, e embora comprovem a influência do cinema nos polissistemas literários, por vezes não vão muito além de um momentâneo aquecimento do mercado editorial. Mas o caso específico das adaptações de Tolkien por Jackson e sua penetração no mercado cultural brasileiro teve desdobramentos singulares que nos permitiram investigar mais a fundo as complexas relações que textos de diferentes naturezas estabelecem entre si no âmbito do que chamamos "polissistemas culturais". A peculiaridade do posicionamento da obra de Tolkien no sistema literário brasileiro deriva do fato de $O$ senhor dos anéis, apesar de sua já referida popularidade em seu sistema de origem e nos EUA, ter permanecido praticamente desconhecido pelos leitores brasileiros até as vésperas do lançamento das adaptações de Peter Jackson.

Analisando em retrospecto, é realmente curioso que a obra de Tolkien tenha tido percurso tão inexpressivo no Brasil ao longo do século XX, enquanto se firmava como uma das obras mais populares e admiradas em países de língua inglesa. Ainda mais se levarmos em consideração o fato de a primeira tradução da trilogia para o português ter sido realizada por Antônio Ferreira da Rocha e Luiz Alberto Monjardim para a editora brasileira Artenova. Cerca de vinte anos após a publicação da obra original no Reino Unido, a Artenova publicou sua tradução; curiosamente, a edição brasileira contava com seis volumes, três dos quais criados pelos editores, já que o texto original, idealizado como um romance único, fora dividido em três, a despeito da resistência do autor, como forma de torná-lo mais vendável. Liberdades tradutórias e editoriais à parte, a Artenova foi responsável pela introdução de $O$ senhor dos anéis ao mundo lusófono. Apesar dessa grande realização, no entanto, a empresa encerrou suas atividades pouco depois da publicação do último dos seis volumes. Após esse período (anos 70 e início da década de 80), as únicas traduções de $O$ senhor dos anéis para a língua portuguesa passariam a ser publicadas pela Europa-América, sediada em Lisboa.

Certamente o insucesso das traduções publicadas pela Artenova não se deve a preconceitos ou reservas nacionais em relação a obras literárias em língua inglesa; muitas das obras em posição central em nosso polissistema literário são de origem anglófona e foram introduzidas aqui via tradução. Pode-se aventar a hipótese de que esse mau desempenho editorial derive de uma dificuldade de posicionamento da obra 
traduzida, tendo em vista que a literatura juvenil no Brasil até muito recentemente não se desvinculava da vertente infantil, daí a recorrente classificação de obras tão díspares quanto, por exemplo, as de Ziraldo e de Tolkien sob um mesmo rótulo, genérico e inespecífico, denominado literatura infanto-juvenil. Mesmo assim, outros escritores de fala inglesa lograram garantir seus nichos nesse aparente "saco de gatos", tais como Lewis Carroll ou mesmo o infantilizado e um tanto distorcido Jonathan Swift. Restam incompreendidos, portanto, os motivos para o mau desempenho da Artenova em introduzir Tolkien em nosso sistema literário, e o fato é que a obra-prima do célebre filólogo britânico teve de aguardar mais de uma década até que a movimentação cultural em torno da produção das adaptações cinematográficas de Jackson garantisse o investimento do mercado editorial na publicação de novas traduções. Ainda na década de 90, provavelmente ciente dos movimentos da longa fase de pré-produção da obra de Jackson, a editora Martins Fontes retoma o projeto de introdução de $O$ senhor dos anéis no polissistema literário brasileiro, publicando a saga conforme sua divisão original em três volumes. A partir de 2000, no entanto, já contando com o auxílio da campanha de marketing internacional que preparava o lançamento do primeiro dos longas-metragens (A sociedade do anel, 2001), a editora brasileira demonstraria que o processo de apresentação de Tolkien ao mercado brasileiro não apenas estava concluído, mas havia sido um sucesso, lançando uma sequência de edições revisadas e em novos formatos, inclusive, é claro, aquela que confirmaria a "sinergia" dos diferentes produtos culturais da "marca" Tolkien: a edição em três volumes com capas alusivas aos filmes de Jackson. Lançado o último filme da trilogia ( $O$ retorno do rei), em 2003, passamos a contar não apenas com um novo escritor britânico e uma nova obra de literatura juvenil em nosso polissistema literário, mas se instaurou no mercado cultural uma verdadeira "tolkienmania", verificável nos mais diversos segmentos e mídias, tais como histórias em quadrinhos, videogames e fanfictions. Mais do que isso, no entanto, para provável desgosto dos precursores da Artenova, observou-se ainda que a reintrodução de $O$ senhor dos anéis no sistema literário brasileiro não alimentou apenas o mercado desse romance e dos demais produtos a ele associados, mas catapultou toda a obra de Tolkien, se não ao centro do polissistema literário, certamente ao centro do mercado editorial. Com isso, obras ficcionais e não-ficcionais do escritor britânico até então desconhecidas do público brasileiro (salvo de eventuais consumidores de livros importados), como $O$ hobbit (2000), O silmarillion (2009), Os filhos de Húrin (2009) e As cartas de J. R. R. Tolkien (2006) finalmente foram traduzidas e publicadas por editoras nacionais.

Curiosamente, no entanto, a intensidade desse boom teve outros desdobramentos em solo brasileiro, como o renovado ímpeto à consolidação de uma literatura essencialmente juvenil e a valorização editorial de obras anteriores ou deliberadamente lançadas na esteira de $O$ senhor dos anéis e que exploram contextos, temáticas e mitologias que, ainda que não sejam exclusivos da obra de Tolkien, ganharam notoriedade a partir de seu revival. Assim, obras que exploram mitologias nórdicas, cenários medievais e sagas fantásticas de heróis messiânicos entraram na ordem do dia, e não chegam a surpreender casos como a publicação de As melhores histórias da mitologia nórdica (FRANCHINI e SEGANFREDO, 2005), coletânea lançada sob o auspicioso slogan "a mitologia na qual J. R. R. Tolkien se baseou para escrever $O$ senhor dos anéis".

Percebe-se, com isso, que os efeitos de adaptações de obras literárias para a linguagem cinematográfica são variados, complexos e abrangentes demais para serem abarcados a partir de abordagens exclusivamente focadas na análise dos textos fonte e 
alvo. A abordagem sistêmica proposta por Even-Zohar nos permite mapear, sem a pretensão de esgotamento, a complexa e dinâmica rede de relações entre os textos de diferentes linguagens que alimentam o polissistema cultural.

Embora ainda tenhamos muito a pesquisar quanto ao corpus aqui apresentado, já nos parece acertado concluir que os dados apresentados põem por terra qualquer noção que ainda se pudesse ter quanto à dívida do cinema para com a arte literária. Ainda que a adaptação de $O$ senhor dos anéis para o cinema possa não ter tido maiores implicações em sistemas culturais em que a obra literária já gozava de sólida popularidade, algo que não nos cabe analisar aqui, acreditamos que o fenômeno cultural que gerou no Brasil não apenas é digno de nota e de estudo, mas deve ser saudado calorosamente. Isso porque uma nação onde cerca de $40 \%$ dos estudantes informam ter menos de dez livros em casa $^{2}$, contabilizadas aqui inclusive obras didáticas, não está em posição de alimentar preconceitos contra quaisquer produtos culturais que possam aquecer o mercado editorial e estimular o interesse pela leitura. $\mathrm{O}$ lançamento da trilogia de Peter Jackson no Brasil teve, a um só tempo, o mérito de sustentar a introdução de um nova obra de literatura juvenil ao nosso sistema literário, apresentar-nos um riquíssimo universo fantástico que tem influenciado muitas outras obras e estimular a formação e qualificação de novos leitores, superando com folga os eventuais e tímidos esforços governamentais em prol da leitura.

Se é verdade que vivemos uma "crise do livro", como nos informa Leyla Perrone-Moisés (1997, p. 87), então talvez devamos nos despir de preconceitos infundados e olhar para o cinema não mais como o primo pobre e devedor da rica literatura, mas como uma possível salvação para o legado literário cada vez mais em desuso. Nesse sentido, pode-se dizer que também a tradução intersemiótica, e não apenas a incensada tradução poética, pode, por meio de adaptações cinematográficas, levar a cabo a tarefa primordial da prática tradutória segundo o filósofo Walter Banjamin (2000): garantir a sobrevida do texto literário. Embora o espírito romântico de Benjamin não tivesse em mente temas comezinhos como o mercado editorial, a qualquer mentalidade mais pragmática parecerá lógico concluirmos que, sem leitores, não há texto que sobreviva.

\section{BIBLIOGRAFIA}

ANDRADE, Oswald de. Manifesto antropófago e manifesto da poesia pau-brasil. [Online]. Disponível em: http://www.ufrgs.br/cdrom/oandrade/oandrade.pdf. Arquivo acessado em 20 de setembro de 2011.

BENJAMIN, Walter. The Task of the Translator. In: VENUTI, Lawrence (ed.). The Translation Studies Reader. London: Routledge, 2000.

CANDIDO, Antonio. Literatura comparada. In: __. Recortes. São Paulo: Companhia das Letras, 1993.

EVEN-ZOHAR, Itamar. Polysystem Theory and Culture Research. In: . Papers in Culture Research. Tel Aviv: Unit of Culture Research - Tel Aviv University, 2010.

[Online]. Disponível em: http://www.tau.ac.il/ itamarez/works/books/EZ-CR-

\footnotetext{
${ }^{2}$ Conforme dados do PISA 2010, 39,5\% dos estudantes brasileiros têm menos de dez livros em casa; outros 30,4\% informaram que o número de livros não ultrapassa 25.
} 
2005_2010.pdf. Arquivo acessado em 20 de setembro de 2010.

. The Position of Translated Literature within the Literary Polysystem. In:

Papers in Historical Poetics. Tel Aviv: The Porter Institute for Poetics, 1978. [Online]. Disponível em: http://www.tau.ac.il/ itamarez/works/books/php1978.pdf. Arquivo acessado em 20 de setembro de 2010.

FRANCHINI, A. S. e SEGANFREDO, C. As melhores histórias da mitologia nórdica. 4 ed. Porto Alegre: Artes e Ofícios, 2005.

HORKHEIMER, Max e ADORNO, Theodore. A indústria cultural: o iluminismo como mistificação de massas. In: ADORNO, Theodore et al. Teoria da cultura de massa. 5 ed. Introdução, comentários e seleção de Luiz Costa Lima. São Paulo: Paz e Terra, 2000.

HUNTER, I. Q. Post-Classical Fantasy Cinema: The Lord of the Rings. In: CARTMELL, Deborah and WHELEHAN, Imelda. The Cambridge Companion to Literature on Screen. New York: Cambridge University Press, 2007.

INDRUSIAK, Elaine B. Looking for Richard e Shakespeare in Love: Shakespeare pela ótica do cinema hollywoodiano pós-modernista. 147 f. Dissertação (Mestrado em Literatura Comparada) - Instituto de Letras, Universidade Federal do Rio Grande do Sul, Porto Alegre, 2001.

Narrativas de efeito: diálogos entre o conto literário e o suspense de longa metragem. 222 f. Tese (Doutorado em Literatura Comparada) - Instituto de Letras, Universidade Federal do Rio Grande do Sul, Porto Alegre, 2009.

PERRONE-MOISÉS, Leyla. A crítica literária hoje. In: V CONGRESSO DA ABRALIC, Rio de Janeiro, 1996. Anais... Rio de Janeiro: UFRJ, 1997.

MAST, Gerald. Literature and Film. In: BARRICELLI, Jean-Pierre and GIBALDI, Joseph (eds.). Interrelations of Literature. New York: MLA, 1982.

METZ, Christian. A significação no cinema. São Paulo: Perspectiva, 1972.

SANTAELLA, Lúcia. Texto. In: JOBIM, José Luís. Palavras da crítica. Rio de Janeiro: Imago, 1992.

WEINHARDT, Marilene e CARDOSO, Mauricio (orgs.). Centro, centros: literatura e literatura comparada em discussão. Curitiba: UFPR, 2011.

TOLKIEN, J. R. R. Cartas de J. R. R. Tolkien. Curitiba: Arte e Letra, 2006. O senhor dos anéis. São Paulo: Martins Fontes, 2001.

. O hobbit. São Paulo: Martins Fontes, 2002.

. O silmarillion. São Paulo: Martins Fontes, 2009.

Os filhos de Húrin. São Paulo: Martins Fontes, 2009.

The Lord of the Rings: $50^{\text {th }}$ Anniversary One-Volume Edition. New York: Houghton Mifflin Co., 2004.

OECD Programme for International Student Assessment (PISA). [Online]. Disponível em: $\quad$ www.pisa.oecd.org/pages/0,2987,en_32252351_32235731_1_1_1_1_1,00.html. Arquivo acessado em 20 de setembro de 2010.

\section{FILMOGRAFIA}

O SENHOR dos anéis: a sociedade do anel. Direção: Peter Jackson. Roteiro: Fran Walsh, Philippa Boyens, Peter Jackson. New Zealand / USA: New Line Cinema, 2001. 1 DVD (179 min.), son., color., legendado. Título original: The Lord of the Rings - The 
Fellowship of the Ring.

O SENHOR dos anéis: as duas torres. Direção: Peter Jackson. Roteiro: Fran Walsh, Philippa Boyens, Stephen Sinclair, Peter Jackson. New Zealand / USA / Germany: New Line Cinema, 2002. 1 DVD (179 min.), son., color., legendado. Título original: The Lord of the Rings - The Two Towers.

O SENHOR dos anéis: o retorno do rei. Direção: Peter Jackson. Roteiro: Fran Walsh, Philippa Boyens, Peter Jackson. New Zealand / USA / Germany: New Line Cinema, 2003. 1 DVD (202 min.), son., color., legendado. Título original: The Lord of the Rings - The Return of the King. 